\title{
Políticas públicas para pessoas idosas no Brasil: uma revisão integrativa
}

\author{
Public policies for the elderly in Brazil: an integrative review
}

Luana Machado Andrade ${ }^{1}$

Edite Lago da Silva Sena ${ }^{2}$

Gleide Magali Lemos Pinheiro ${ }^{2}$

Edmeia Campos Meira ${ }^{2}$

Lais Santana Santos Pereira Lira ${ }^{2}$

\footnotetext{
${ }^{1}$ Faculdade de Tecnologia e Ciências, Colegiado do Curso de Enfermagem, Jequié BA.

R. Antônio Orrico 357, São Judas Tadeu. 45.200-000 Jequié BA Brasil. luanamachado87@hotmail.com ${ }^{2}$ Departamento de Saúde, Universidade Estadual do Sudoeste da Bahia.
}

\begin{abstract}
This paper is an integrative review analyzing the scientific production and legal documents regarding public policies for the elderly in Brazil. Research was conducted in the Virtual Health Library and Scopus databases, examining publications since 2003. Data were collected from June to September of 2011 using the following key words: "elderly" (idosos), "public policies" (políticas públicas), "elderly person" (pessoa idosa), "aging" (envelhecimento) and "civic participation” (participação cidadã). The search resulted in the selection of 15 articles and six legal documents targeted at the elderly in Brazil that were submitted to content analysis by categorization. The results revealed that aging in Brazil has occurred in the midst of adaptations entrenched in cultural biases, social, economic and educational discrepancies and the implementation of public welfare policies. There were few studies that indicated the importance of strengthening social movements that elicit discussion related to the elderly in Brazil. The conclusion reached is that the study will provide material for reflection about the construction of a new reality about aging in Brazil. Key words Aging, Public policy, Civic participation
\end{abstract}

Resumo Trata-se de uma revisão integrativa que objetiva analisar o que versam as produções científicas e os documentos legais sobre as politicas públicas para as pessoas idosas no Brasil. Realizou-se uma busca nas bases de dados da Biblioteca Virtual em Saúde e do Scopus, considerando publicações a partir de 2003. Os dados foram coletados no período de junho a setembro de 2011 utilizando os seguintes descritores: idosos (elderly), "políticas públicas" ("public policy"), "pessoa idosa" ("elderly person"), envelhecimento (aging) e "participação cidadã" ("citizen participation”). A busca resultou na seleção de 15 artigos e seis documentos legais direcionados à pessoa idosa no Brasil que foram submetidos à análise de conteúdo por categorização. Os resultados demonstraram que o envelhecimento no Brasil tem ocorrido em meio a adaptações arraigadas de preconceitos culturais, discrepâncias socioeconômicas e educacionais e a implementação de politicas públicas assistencialistas. Poucos foram os trabalhos que indicaram a importância do fortalecimento de movimentos sociais que estimulam discussões relacionadas aos idosos em nosso país. Concluí-se que o estudo fornecerá subsídios para reflexões acerca da construção de uma nova realidade sobre o envelhecimento no Brasil.

Palavras-chave Envelhecimento, Políticas públicas, Participação cidadã 


\section{Introdução}

O envelhecimento populacional é definido como a mudança na estrutura etária da população, na qual se observa um aumento do peso relativo de pessoas acima de determinada idade, considerada como definidora do início da velhice ${ }^{1}$. Nas últimas três décadas, esse fenômeno vem acontecendo no Brasil de forma mais rápida e intensa, sendo que o número absoluto de pessoas com 60 anos aumentou, em média, nove vezes ${ }^{2}$.

De acordo com Instituto Brasileiro de Geografia e Estatística (IBGE), no ano de 2000 o contingente de pessoas com mais de 60 anos, no Brasil, alcançava cerca de 15 milhões, e em 2010 a proporção de idosos tinha aumentado de $8,6 \%$ para $11 \%$, sendo que, no grupo etário com 80 anos ou mais, o crescimento chegou a quase $65 \%$. Em números absolutos, alcançamos em 2010 mais de 20 milhões de idosos ${ }^{3}$.

Com relação aos países desenvolvidos, a exemplo da França, o aumento da população idosa de $7 \%$ para $14 \%$ do total se deu em mais de um século, já no Brasil, essa mesma variação demográfica ocorrerá nas próximas duas décadas (entre 2011 e 2031)4. A população idosa irá mais do que triplicar, de menos de 20 milhões em 2010 para aproximadamente 65 milhões em 2050.

Outro fator preponderante é que o acelerado processo de envelhecimento brasileiro vem acontecendo em meio a sérias dificuldades de expansão do sistema de proteção social para todos os grupos etários, em particular para os idosos, situação que também difere do ocorrido nos países desenvolvidos. No continente europeu o envelhecimento populacional encontrou um cenário socioeconômico favorável, que permitiu a expansão dos seus sistemas de proteção social, facilitando o acesso e impactando na qualidade dos serviços oferecidos ${ }^{5}$. Apesar de se observar uma melhora consubstancial na economia brasileira nos últimos anos, a estrutura dos serviços de atenção ao idoso ainda estão aquém das necessidades apresentada por esse grupo etário, situação que demonstra a necessidade de investimento urgente frente ao fenômeno populacional previsto para os próximos anos.

Concomitante, as alterações demográficas incidem diretamente nos perfis epidemiológico, econômico e social peculiar a esta faixa etária em ascensão. Do ponto de vista dos fatores que determinam a saúde da população idosa em países em desenvolvimento, percebe-se que ao longo da vida as características do contexto social, que geram desigualdades nas exposições e vulnerabili- dades, são as que mais interferem no seu bemestar, na independência funcional e na sua qualidade de vida ${ }^{6}$. Desse modo, torna-se imperativo exigir que governantes e sociedade encontrem formas de materializar as leis que garantem proteção e efetivação dos direitos da pessoa idosa, bem como a necessidade de discutir e divulgar os documentos legais que regulamentam as políticas públicas direcionadas à promoção do bem estar, garantia de respeito e dignidade aos idosos brasileiros.

A deficiência no que tange à efetivação dos direitos essenciais a este segmento populacional deixa evidente a necessidade de estudos que direcionem a população para lutar a favor daquilo que há de mais justo na vida dos seres humanos: a certeza de que todos envelhecem a cada momento.

Diante de tais considerações, este estudo objetivou analisar o que versam as produções científicas e os documentos oficiais sobre as políticas públicas para as pessoas idosas no Brasil.

Uma pesquisa desse caráter apresentará uma síntese do conhecimento produzido com relação aos aspectos políticos que tangem o envelhecimento no Brasil, promoverá atualização dos profissionais de saúde e da comunidade acadêmica por meio de uma visão prévia do estado da arte em relação ao tema proposto e fornecerá subsídios para novas pesquisas nesta área, fundamental diante das mudanças sociodemográficas vivenciadas nos dias atuais.

\section{Métodos}

Trata-se de uma revisão integrativa, com base em produções científicas selecionadas nas bases de dados da Biblioteca Virtual em Saúde (BVS) e da Scopus, e em um levantamento documental de decretos, leis, portarias e resoluções em âmbito nacional específica para a pessoa idosa.

A coleta de dados foi realizada entre os meses de junho a setembro de 2011 e, para as pesquisas nas bases de dados utilizaram-se Descritores em Ciências da Saúde (DECS), de forma combinada, sendo eles: idosos and "políticas públicas" (elderly and public policy), "pessoa idosa" and "políticas públicas" (elderly person and public policy), envelhecimento and "políticas públicas" (aging and public policy), "participação cidadã" and "pessoa idosa" (citizen participation and older person), "participação cidadã" and idosos (citizen participation and elderly), "participação cidadã" and envelhecimento (citizen participation 
and envelhecimento) e "direitos dos idosos" ( $r i-$ ghts of the elderly).

A seleção dos artigos baseou-se nos seguintes critérios: artigos publicados a partir de 2003, tendo em vista a promulgação da Lei 10.741 que apresenta o Estatuto do Idoso como um marco na história das políticas públicas para essa faixa etária no Brasil, delimitando um recorte temporal de oito anos (2003 a 2011); estar em língua portuguesa, devido ao objetivo da pesquisa restringir-se ao âmbito nacional; e, envolver em seu resumo aspectos do processo de envelhecimento, no que tangem as questões sociais, econômicas, culturais e demográficas, bem como, abordagens referentes à participação e efetivação dos seus direitos. Foram excluídas abordagens específicas sobre doenças, institucionalização e estudos em outros países, bem como, teses, dissertações e monografias.

Com relação aos documentos legais, foram incluídos aqueles que regulamentam de forma ampla as políticas nacionais da pessoa idosa, envolvendo questões de saúde e cidadania, selecionando-se duas leis, dois decretos e duas portarias.

Os trabalhos utilizados foram sistematizados em dois quadros. O Quadro 1, que apresenta os artigos selecionados, é composto das seguintes informações: combinação dos descritores, referência do artigo/autor (conforme citação) e objetivos. O Quadro 2, que apresenta os documentos legais, contém o título da legislação, a sua proposta principal e uma síntese do seu conhecimento.

A análise do material buscou caracterizar as produções levando em consideração os achados por combinação de descritores, local de publicação, ano e abordagens que, por sua vez, deram origem à construção de três categorias analisadas sob a perspectiva dos principais documentos legais selecionados, utilizando como referência metodológica o método de Análise de Conteúdo por categorização proposto por Bardin ${ }^{7}$.

\section{Resultados e discussão}

Como resultado da pesquisa, inicialmente, encontrou-se 338 estudos, sendo 211 das bases da BVS e 127 no SCOPUS. A partir dos critérios estabelecidos para restringir a pesquisa, foram selecionados 15 artigos (Quadro 1) e seis documentos legais, sendo eles: a Lei $8.842 / 94^{8}$ regulamentada pelo Decreto 1.948/969 (Política Nacional do Idoso), o Decreto 4.227/2002 ${ }^{10}$ (Conselho Nacional dos Direitos dos Idosos), a Lei 10.741/
$03^{11}$ (Estatuto do Idoso), a Portaria 399/GM ${ }^{12}$ (Diretrizes do Pacto Pela Saúde) e a Portaria 2.528/ $06^{13}$ (Política Nacional de Saúde da Pessoa Idosa) que revoga a Portaria 1.395/9914 (Política de Saúde do Idoso) (Quadro 2).

Com relação aos artigos identificou-se que $33 \%$ dos trabalhos foram publicados no ano de $2010^{15-19}, 26 \%$ no ano de $2009^{8,20-22}, 20 \%$ no ano de $2007^{23-25}, 13 \%$ em $2006^{26,27}$ e apenas $6 \%$ em $2008^{18}$, configurando ausência de publicações selecionadas para esta abordagem nos anos de 2003, 2004 e 2005 que também faziam parte do recorte temporal.

Quanto aos aspectos relativos às bases de dados, percebe-se uma equivalência de publicações em quase todos os descritores associados, com exceção das associações envolvendo o DECS “Participação Cidadã”, onde foram encontrados apenas $6 \%$ dos artigos ${ }^{18}$, sendo que, envelhecimento AND "Participação Cidadã" não apresentou nenhuma publicação. Desse modo, podemos apontar para a necessidade de pesquisas envolvendo as questões de cidadania entre os idosos e suas configurações na área das políticas públicas.

Ressalta-se ainda que, entre as produções selecionadas, $20 \%$ foram produzidas e publicadas na região Centro-Oeste ${ }^{15,17,27}, 13 \%$ no Sudes$\mathrm{te}^{19,24}, 6 \%$ no Sul $^{12}$ e Nordeste ${ }^{22}$, evidenciando uma carência de publicações e pesquisas, principalmente, na região Nordeste que, por sua vez, é a segunda maior detentora de participação da população idosa do país, concentrando quase $29 \%$ de pessoas da terceira idade vivendo em condições socioeconômicas desfavoráveis ${ }^{13,28}$. Os $55 \%$ restantes não apresentavam o local da realização da pesquisa em sua metodologia ${ }^{16,18,21,23,25,26,29,30}$.

Em relação às abordagens encontradas destacamos que $28 \%$ discutem a legislação brasileira e políticas públicas direcionadas para os idosos ${ }^{19-}$ 21, 26,27; outros $26 \%$ trazem considerações relativas às mudanças no perfil demográfico e sua influência nos aspectos bio-psico-socio-culturais e econômicos do envelhecimento no país ${ }^{15,16,25,29}$; deixando aos $46 \%$ restantes reflexões sobre as relações do envelhecimento e a saúde no Brasil $(26 \%)^{17,22,23,29}$, bem como, os movimentos sociais dos idosos, efetivação de seus direitos e a conquista da cidadania $(13 \%)^{18,24}$. O Quadro 1 apresenta os estudos analisados acima.

Após a caracterização dos artigos, realizouse uma leitura dos documentos legais para discutir as abordagens encontradas nos estudos, que deram origem a três grandes categorias: o processo de envelhecimento no Brasil; políticas públicas de saúde para a pessoa idosa; e, participa- 
Quadro 1. Informações sobre os artigos selecionados na pesquisa.

\begin{tabular}{|c|c|c|}
\hline DECS & $\begin{array}{l}\text { Referência do } \\
\text { artigo/autor(es) }\end{array}$ & Objetivos \\
\hline \multirow{4}{*}{$\begin{array}{l}\text { "Idosos" } \\
\text { AND } \\
\text { "Políticas Públicas" }\end{array}$} & (25) / Veras R. & $\begin{array}{l}\text { Examinar a nova realidade demográfica e epidemiológica } \\
\text { brasileira. }\end{array}$ \\
\hline & $\begin{array}{l}\text { (24) / Machado } \\
\text { MAN. }\end{array}$ & $\begin{array}{l}\text { Analisar as várias formas de participação e organização dos } \\
\text { idosos, com ênfase nas Associações de Aposentados e no } \\
\text { Grande Conselho Municipal dos Idosos de São Paulo. }\end{array}$ \\
\hline & $\begin{array}{l}\text { (20) / Alencar } \\
\text { MSS, Carvalho } \\
\text { CMRG. }\end{array}$ & $\begin{array}{l}\text { Refletir sobre as políticas públicas e o fenômeno do } \\
\text { envelhecimento, tomando por base os campos } \\
\text { conceituais,sociodemográficos e político-educacional. }\end{array}$ \\
\hline & $\begin{array}{l}\text { (17) / Camacho } \\
\text { ACLF, Coelho MJ. }\end{array}$ & $\begin{array}{l}\text { Analisar o desenvolvimento dos programas de saúde do idoso } \\
\text { com base nas referências contidas nas principais bases de dados. }\end{array}$ \\
\hline \multirow{2}{*}{$\begin{array}{l}\text { "Pessoa Idosa" } \\
\text { AND "Políticas } \\
\text { Públicas" }\end{array}$} & $\begin{array}{l}\text { (23) / Martins JJ } \\
\text { et al . }\end{array}$ & $\begin{array}{l}\text { Refletir acerca do agir em saúde, a partir da articulação do Artigo } \\
18 \text { do Estatuto do Idoso com as atuais Políticas Públicas } \\
\text { dirigidas à pessoa que envelhece em nosso país. }\end{array}$ \\
\hline & $\begin{array}{l}\text { (16) / Laranjeira } \\
\text { CA. }\end{array}$ & $\begin{array}{l}\text { Desvelar os principais debates culturais sobre a velhice, sob a } \\
\text { análise das estruturas ideológicas dicotômicas entre o } \\
\text { envelhecimento e a velhice. }\end{array}$ \\
\hline \multirow{3}{*}{$\begin{array}{l}\text { "Envelhecimento" } \\
\text { AND "Políticas } \\
\text { Públicas" }\end{array}$} & (29) / Kalache A. & $\begin{array}{l}\text { Apresentar os eixos que têm norteado as discussões no campo } \\
\text { da Demografia e que trazem implicações para a Saúde Pública. }\end{array}$ \\
\hline & (30) / Veras R. & $\begin{array}{l}\text { Discutir as consequências sociais e, particularmente, da saúde, } \\
\text { decorrentes da ampliação do número de idosos no Brasil em um } \\
\text { curto período. }\end{array}$ \\
\hline & $\begin{array}{l}\text { (15) /Alves VP, } \\
\text { Vianna LG. }\end{array}$ & $\begin{array}{l}\text { O artigo sugere a elaboração de políticas públicas para a } \\
\text { educação gerontológica, buscando o significado do } \\
\text { envelhecimento e sua correlação com a existência ou não de } \\
\text { preconceitos para esses dois grupos. }\end{array}$ \\
\hline $\begin{array}{l}\text { "Participação } \\
\text { Cidadã" } \\
\text { AND } \\
\text { "Pessoa Idosa" } \\
\text { "Participação } \\
\text { Cidadã" } \\
\text { AND “Idosos" }\end{array}$ & (18) / Telles JL. & $\begin{array}{l}\text { O artigo traz um comentário sob a perspectiva dos movimentos } \\
\text { sociais da população idosa diante da análise realizada por } \\
\text { Minayo e Souza acerca da temática violência à luz das políticas } \\
\text { públicas no Brasil a partir de } 1994 \text {, quando foi instituída a } \\
\text { Política Nacional do Idoso (PNI) através da Lei no } 8.842 \text {. }\end{array}$ \\
\hline \multirow{5}{*}{$\begin{array}{l}\text { "Direitos dos } \\
\text { Idosos" }\end{array}$} & $\begin{array}{l}\text { (27) / Camargos } \\
\text { et al. }\end{array}$ & $\begin{array}{l}\text { Avaliar as políticas públicas de atenção à pessoa idosa, bem } \\
\text { como sua evolução, tendo como ambiência o Estatuto do Idoso. }\end{array}$ \\
\hline & $\begin{array}{l}\text { (17) / Souza } \\
\text { Júnior DGS et al. }\end{array}$ & $\begin{array}{l}\text { Analisar as propostas destinadas à população idosa nas agendas } \\
21 \text { Global e Brasileira em seus respectivos capítulos. }\end{array}$ \\
\hline & $\begin{array}{l}\text { (22) / Moimaz } \\
\text { SAS et al. }\end{array}$ & $\begin{array}{l}\text { Pesquisar a legislação federal brasileira, atualmente em vigor, } \\
\text { acerca dos direitos dos idosos relacionados à saúde, } \\
\text { considerando a definição da Organização Mundial de Saúde } \\
\text { (OMS). }\end{array}$ \\
\hline & $\begin{array}{l}\text { (21) Cielo PFLD, } \\
\text { Vaz ERC }\end{array}$ & $\begin{array}{l}\text { Identificar no campo legislativo brasileiro abordagens acerca dos } \\
\text { direitos do idoso, considerando os mecanismos e meios de } \\
\text { proteção instituídos especialmente depois da aprovação do } \\
\text { Estatuto do Idoso. }\end{array}$ \\
\hline & $\begin{array}{l}\text { (19) / Martins } \\
\text { MS, Massarollo, } \\
\text { MCKB. }\end{array}$ & $\begin{array}{l}\text { Identificar o conhecimento de idosos sobre seus direitos e se } \\
\text { consideram que esses direitos são respeitados }\end{array}$ \\
\hline
\end{tabular}


Quadro 2. Documentos legais sobre a pessoa idosa no Brasil.

\begin{tabular}{|c|c|c|}
\hline Legislação & Proposta & Síntese \\
\hline $\begin{array}{l}\text { Lei } 8.842 / 94^{8} \\
\text { regulamentada } \\
\text { pelo Decreto } \\
1.948 / 96\end{array}$ & $\begin{array}{l}\text { Dispõe sobre a política } \\
\text { nacional do idoso, cria o } \\
\text { Conselho Nacional do } \\
\text { Idoso e dá outras } \\
\text { providências. }\end{array}$ & $\begin{array}{l}\text { Define princípios e diretrizes que asseguram os } \\
\text { direitos sociais da pessoa maior de } 60 \text { anos. Sua } \\
\text { principal característica baseia-se na perspectiva de } \\
\text { responder às necessidades dos idosos mediante } \\
\text { programas e ações de diferentes tipos numa } \\
\text { perspectiva intersetorial que envolva a Previdência e } \\
\text { Assistência Social, Saúde, Trabalho, Justiça, } \\
\text { Planejamento, Cultura e outros. }\end{array}$ \\
\hline $\begin{array}{l}\text { Decreto } 1.948 / 96^{9} \\
\text { (Política Nacional } \\
\quad \text { do Idoso) }\end{array}$ & $\begin{array}{l}\text { Regulamenta a Lei no } \\
\text { 8.842, de } 04 \text { de janeiro de } \\
\text { 1994, que dispõe sobre a } \\
\text { Política Nacional do Idoso, } \\
\text { e dá outras providências. }\end{array}$ & $\begin{array}{l}\text { Nesta regulamentação, são atribuídas as competências } \\
\text { dos órgãos e entidades públicas para a implementação } \\
\text { da PNI, e ela ainda remete ao Conselho Nacional de } \\
\text { Seguridade e aos conselhos setoriais, no âmbito da } \\
\text { seguridade, a formulação, coordenação, supervisão e } \\
\text { avaliação da Política Nacional do Idoso, respeitadas as } \\
\text { respectivas esferas de atribuições administrativas. }\end{array}$ \\
\hline $\begin{array}{l}\text { Decreto } 4.227 / 02^{10} \\
\text { (Conselho } \\
\text { Nacional dos } \\
\text { Direitos dos } \\
\text { Idosos) }\end{array}$ & $\begin{array}{l}\text { Cria o Conselho Nacional } \\
\text { dos Direitos do Idoso } \\
\text { (CNDI), e dá outras } \\
\text { providências. }\end{array}$ & $\begin{array}{l}\text { Regulamenta o Conselho Nacional dos Direitos dos } \\
\text { Idosos que apresenta-se como estratégia de } \\
\text { mobilização social e de participação efetiva nas } \\
\text { políticas públicas. }\end{array}$ \\
\hline $\begin{array}{l}\text { Lei } 10.741 / 03^{11} \\
\text { (Estatuto do } \\
\text { Idoso) }\end{array}$ & $\begin{array}{l}\text { Dispõe sobre o Estatuto do } \\
\text { Idoso e dá outras } \\
\text { providências. }\end{array}$ & $\begin{array}{l}\text { Amplia a resposta do Estado e da sociedade às } \\
\text { necessidades dos idosos. Trata dos mais variados } \\
\text { aspectos da sua vida, abrangendo desde direitos } \\
\text { fundamentais até o estabelecimento de penas para } \\
\text { crimes mais comuns cometidos contra as pessoas } \\
\text { idosas. }\end{array}$ \\
\hline $\begin{array}{l}\text { Portaria } 399 / \mathrm{GM} / \\
06^{12} \text { (Diretrizes do } \\
\text { Pacto Pela Saúde) }\end{array}$ & $\begin{array}{l}\text { Divulga o Pacto pela Saúde } \\
2006 \text { - Consolidação do } \\
\text { SUS e aprova as Diretrizes } \\
\text { Operacionais doReferido } \\
\text { Pacto. }\end{array}$ & $\begin{array}{l}\text { No que tange a saúde do idoso, esta portaria contem o } \\
\text { Pacto pela Vida que traz como um dos seus } \\
\text { compromissos a Implantação da Política Nacional de } \\
\text { Saúde da Pessoa Idosa, buscando a atenção integral. }\end{array}$ \\
\hline $\begin{array}{l}\text { Portaria } 2.528 / 06^{13} \\
\text { (Política Nacional } \\
\text { de Saúde da Pessoa } \\
\text { Idosa) }\end{array}$ & $\begin{array}{l}\text { Aprova a Política Nacional } \\
\text { de Saúde da Pessoa Idosa }\end{array}$ & $\begin{array}{l}\text { Tem como principal finalidade, recuperar, manter e } \\
\text { promover a autonomia e a independência dos } \\
\text { indivíduos idosos, direcionando medidas coletivas e } \\
\text { individuais de saúde para esse fim, em consonância } \\
\text { com os princípios e diretrizes do Sistema Único de } \\
\text { Saúde. É alvo dessa política todo cidadão e cidadã } \\
\text { brasileiros com } 60 \text { anos ou mais de idade. }\end{array}$ \\
\hline
\end{tabular}

ção social na velhice. A seguir o Quadro 2 sumariza os documentos legais utilizados que precedem a análise dos dados.

\section{O processo de envelhecimento no Brasil}

Os idosos diferem de acordo com a sua história de vida, o seu grau de independência funcional e a demanda por serviços mais ou menos específicos $^{13}$. Como um conjunto de fatores bio- lógicos, físicos, psicológicos e sociais, o envelhecimento, nem sempre atua de maneira concorrente em todos os indivíduos, podendo até mesmo descaracterizar um individuo de 70 anos como velho, ou até mesmo caracterizar outro aos 50 anos como tall ${ }^{23}$.

Desse modo, o envelhecimento é antes um estado próprio do ser humano idoso, que apresenta especificidades socioeconômicas, culturais, ambientais, individuais e/ou coletivas segundo 
épocas e lugares e apresenta-se em cada ser humano de modo singular e único ${ }^{13,15}$.

No Brasil, para fins de levantamentos demográficos, considera-se idoso o corte definido pela OMS (Organização Mundial da Saúde) e, posteriormente, pelo Estatuto do Idoso, aquele individuo com idade a partir de $60 \operatorname{anos}^{26,31}$.

Para tanto, a PNSI afirma que não se fica velho aos 60 anos, tendo em vista que o envelhecimento é um processo natural que ocorre ao longo de toda a experiência de vida do ser humano, por meio de escolhas e de circunstâncias ${ }^{13}$.

Além das caracterizações quanto ao processo de envelhecimento, outro aspecto bastante evidenciado nos estudos refere-se à imagem sociocultural que se tem da velhice, detectados pela existência de preconceitos e estereótipos ${ }^{15,16,20}$.

O preconceito contra a velhice e a negação da sociedade quanto a esse fenômeno colaboram para a dificuldade de se pensar políticas específicas para esse grupo. Ainda há os que pensam que se investe na infância e se gasta na velhice ${ }^{13}$. Daí o cuidado na formação que se deve dar às novas gerações, para que não absorvam o ageism, expressão que deriva do vocábulo inglês age (idade) e designa os processos sociais de marginalização e de construção de estereótipos pejorativos relativos à idade cronológica ${ }^{15,16}$.

Em outro estudo identificamos que este problema não se vincula apenas ao olhar dos demais grupos etários, mas também ao posicionamento dos idosos na sociedade. Estes procuram parecer e agir como os jovens para serem valorizados, perdendo toda noção de inserção social e dignidade nesta fase da vida ${ }^{29}$. O contrário do que ocorre nas sociedades não ocidentais, onde se verifica uma imagem bastante diferente, com aspectos positivos sobre o envelhecimento, onde os idosos não precisam camuflar-se para esconder sua idade com receio das associações depreciativa à velhice do mundo ocidental ${ }^{26}$.

\section{Políticas de saúde para a pessoa idosa}

A Organização Mundial da Saúde define as bases para um envelhecimento saudável, destacando a equidade no acesso aos cuidados de saúde e o desenvolvimento continuado de ações de promoção à saúde e prevenção de doenças ${ }^{25,31}$.

A PNI, a PNSPI e o Estatuto do Idoso são dispositivos que norteiam ações sociais e de saúde, garantem os direitos das pessoas idosas e obrigam o Estado à proteção dos mesmos. Porém, é sabido que a efetivação de uma política pública requer a atitude consciente, ética e cidadã dos envolvidos e interessados em viver envelhecendo de modo mais saudável possível, na qual o Estado, os profissionais da saúde, o idoso e a sociedade em geral sejam coresponsáveis por esse processo $^{23}$.

Desse modo, o envelhecimento nos desafia a produzir políticas de saúde que respondam às necessidades das pessoas idosas, já que a proporção de usuários idosos de todos os serviços prestados tende a ser cada vez maior, quer pelo maior acesso às informações do referido grupo etário, quer pelo seu expressivo aumento relativo e absoluto na população brasileira ${ }^{13,25}$.

A velhice não necessita da totalidade de sua reserva funcional para viver bem e com qualidade e não deve ser considerada como doença, pois as enfermidades mais comuns nessa etapa da vida são preveníveis, diagnosticáveis e tratáveis ${ }^{23,29}$. À medida que as tendências demográficas aceleram, há um aumento na prevalência de doenças crônicas, o que implica a urgência de priorizar a prevenção em todos os países, no entanto, apesar de preconizar suas prioridades para atenção básica, o SUS é orientado pelo imediatismo, com ênfase no cuidado agudo, e não na prevenção e no cuidado crônico ${ }^{17,29}$.

No âmbito da saúde, a $\mathrm{PNI}^{17}$, destaca em seu Capítulo IV a necessidade de "garantir ao idoso a assistência à saúde, nos diversos níveis de atendimento do SUS; prevenir, promover, proteger e recuperar a saúde do idoso, mediante programas e medidas profiláticas; incluir a Geriatria como especialidade clínica, para efeito de concursos públicos federais, estaduais, municipais e do Distrito Federal; realizar estudos para detectar o caráter epidemiológico de determinadas doenças do idoso, com vistas à prevenção, tratamento e reabilitação; criar serviços alternativos de saúde para o idoso".

Posteriormente, em 2002, é proposta a organização e a implantação de Redes Estaduais de Assistência à Saúde do Idoso (Portaria no 702/ SAS/MS ${ }^{32}$, de 2002), tendo como base as condições de gestão e a divisão de responsabilidades definida pela Norma Operacional de Assistência à Saúde (NOAS) e, como parte de operacionalização das redes, são criadas as normas para cadastramento de Centros de Referência em Atenção à Saúde do Idoso (Portaria no 249/SAS/MS ${ }^{14}$, de 2002) ${ }^{13}$.

Após muitas tentativas de fornecer atenção integral e específica à população idosa, surgem as Diretrizes do Pacto Pela Saúde, por meio da Portaria no 399/GM ${ }^{12}$, que contemplam o Pacto pela Vida, em que é afirmada a necessidade de 
enfrentamento dos desafios impostos por um processo de envelhecimento ora caracterizado por doenças e/ou condições crônicas não transmissíveis, porém passíveis de prevenção e controle, e por incapacidades que podem ser evitadas ou minimizadas ${ }^{13,23}$.

Entretanto, ainda são muitas as questões que acompanham o envelhecimento da população ${ }^{30}$. Desse modo, em outubro de 2006, o Ministro da Saúde revoga a PNSI e, com base no Estatuto do Idoso, que fortalece ações para garantir à pessoa idosa proteção à vida e à saúde, aprova a PNSPI, a qual assume que o principal problema que pode afetá-lo, em consequência da evolução de suas enfermidades e de seu estilo de vida, é a perda de sua capacidade funcional - perda das habilidades físicas e mentais necessárias à realização de suas atividades básicas e instrumentais diárias ${ }^{14,29,31}$.

\section{Participação social na velhice}

A participação social já é marcante na legislação brasileira desde a Constituição de $1988^{33}$, que trata no Capítulo II da Seguridade Social, artigo 194, que esta organização deve-se basear no "caráter democrático e descentralizado da gestão administrativa, com a participação da comunidade, em especial de trabalhadores, empresários e aposentados"14. Desse modo, o texto constitucional assegura sua participação na comunidade, defendendo sua dignidade e bem-estar e garantindo-lhes o direito à vida como fundamentos do Estado Democrático de Direito ${ }^{21}$.

A inclusão da pessoa idosa é tratada, ainda, na PNI, cujo principal objetivo era garantir os direitos sociais promovendo sua independência e inserção social ${ }^{21,27}$. Esta mesma Lei previa a criação do Conselho Nacional do Idoso e fazia referência aos Conselhos Estaduais e Municipais e do Distrito Federal, com um conjunto de ações governamentais que deveriam implementar as políticas para a pessoa idosa em várias áreas, como assistência social, habitação, saúde, educação, cultura, lazer e previdência social ${ }^{14,17}$. Mais adiante, a regulamentação do CNDI foi feita através do Decreto de $n^{\circ} 4.227^{10}$, de 13 de maio de 2002, pelo então presidente da República Fernando Henrique Cardoso ${ }^{18}$.

Desde então, tanto o CNDI quanto os conselhos estaduais têm buscado estratégias de mobilização social e de participação efetiva nas políticas públicas. De um problema social, a questão da população idosa passa, gradativamente, a ser tratada no âmbito dos direitos de cidadania, que hoje constituem-se como uma das maiores conquistas dessa faixa etária em nosso país ${ }^{18,21}$.

No entanto, ainda assim existe um abismo entre a lei e a realidade dos idosos no Brasil, considerando que a sociedade só será ética quando reconhecer o potencial destes seus membros, quando lutar para que o direito os reconheça como cidadãos e, finalmente, quando todos eles tiverem sua cidadania reconhecida e garantida. Só assim estará conquistado o nosso próprio espaço no futuro e resguardado a nós mesmos um envelhecimento digno ${ }^{21}$.

Desse modo, percebemos que o caminho, contudo, não é nebuloso ou desconhecido. Bastaria que houvesse, por parte da família, da sociedade e do Estado, um compromisso em implantar uma vida digna para todos os cidadãos ${ }^{26}$. Tudo realmente começa com a efetivação do princípio da dignidade humana ${ }^{21}$.

Para isso contamos com diversos movimentos sociais que se manifestam por meio de Grupos de Convivência e associações. Existe um preconceito em relação ao movimento da terceira idade, referenciado em seu caráter sociocultural e de lazer, não reconhecendo as possibilidades abertas aos idosos de vivenciarem experiências de desenvolvimento pessoal e de descoberta de uma nova maneira de viver com mais autonomia e liberdade 22,27 .

Falar em mobilização social e exercício de cidadania recai, portanto, no contexto sociocultural na qual o idoso foi inserido ao longo de sua vida. É sabido que os idosos presentes em grupos de convivência e na população em geral são, em sua maioria, mulheres, ex-donas de casa que tiveram pouco ou nenhum acesso à educação. Hoje, fazem parte da maioria dos movimentos sociais, no entanto, não foram educadas politicamente para desenvolverem o exercício de sua cidadania e a efetivação dos seus direitos.

Desse modo, a maioria dos estudos selecionados nesta pesquisa apontam para a necessidade de inserção da educação gerontológica desde a infância, até com os próprios idosos. A educação busca vislumbrar a prenhe de possibilidades e de humanidade, num movimento orgânico de ação-reflexão, de trocas, de empoderamento, de inclusão, de transformação incorporada ao dinamismo da vida individual e coletiva, conscientizando-os quanto à sua participação ativa na sua comunidade $\mathrm{c}^{15,16,19,20}$. 


\section{Conclusões do estudo}

Os artigos mostraram que apesar do processo de envelhecimento apresentar-se amplamente discutido no Brasil, país que experimenta a mudança no perfil demográfico e epidemiológico de modo bastante acelerado, o que se percebe é que estas mudanças trazem uma diversidade de alterações em todos os aspectos da sociedade brasileira e mundial.

O Brasil começa então a se preocupar com essas questões e após o período de redemocratização social e incorporação da Constituição de $1988^{33}$, algumas leis vêm sendo implantadas na tentativa de suprir as novas necessidades da tendência mundial e urgência nacional: o envelhecimento.

Para muitos, a palavra envelhecimento arrasta uma série de fatores depreciativos e socialmente descartáveis. No entanto, o que se pretende definitivamente é que este preconceito deixe de circular numa sociedade que daqui a alguns anos terá quase que $30 \%$ da sua população composta por idosos.

O conjunto de políticas, considerada no todo, estatutariamente, marca um compromisso nacional com o fortalecimento da democracia e dos direitos humanos, por intermédio do reconhecimento explícito do respeito às diversas idades.
Trata-se, portanto, de afirmar o compromisso constitucional e democrático de tratamento dos cidadãos idosos, sem distinções fundadas em preferências de gerações etárias: fortalece-se o respeito a todos os homens e mulheres.

As políticas para idosos no Brasil devem seguir em consonância com a realidade de nosso país e primar sempre para uma política de estar saudável, seja biológica, psicológica ou socialmente. Portanto, estar saudável significa combater a gerofobia, assegurando uma política de saúde que considere as características da velhice.

É necessário incentivar nesta população a consolidação de um movimento novo, capaz de colocar questões afetas à vida de todos os idosos, apontar diferenças impostas pelas aposentadorias, os serviços de saúde, a dificuldade ao acesso à cultura e à educação, a falta de respeito nos transportes, construir, efetivamente, outra identidade para os velhos, mostrando ao Estado e à sociedade que podem desempenhar papéis sociais até o fim de suas vidas, sendo produtivos e mais felizes. Participando da política, das universidades abertas, dos grupos de convivência, dos fóruns, dos conselhos e associações de aposentados, dançando, namorando, viajando, fazendo teatro, canto, artes plásticas, enfim, vivendo a vida plenamente, trazendo a política para um novo patamar. 


\section{Colaboradores}

LM Andrade trabalhou na pesquisa, elaboração e redação final; ELS Sena na elaboração, metodologia e redação final; GML Pinheiro na metodologia e redação final; EC Meira na pesquisa e na elaboração; e, LSSP Lira na metodologia e redação final.

\section{Referências}

1. Carvalho JAM, Garcia RA. O envelhecimento da população brasileira: um enfoque demográfico. Cad Saude Publica 2003; 19(3):725-733.

2. Beltrão KI, Camarano AA, Kanso S. Dinâmica populacional brasileira na virada do século XX. Rio de Janeiro: IPEA; 2004.

3. Instituto Brasileiro de Geografia e Estatística (IBGE) 2010. Sinopse do Censo Demográfico 2010. [página na Internet]. 2010. [acessado 2012 mar 27]. Disponível em: http://www.censo2010.ibge.gov.br/ sinopse/index.php? dados $=12 \& u f=00$.

4. Veras RP. Experiências e tendências internacionais de modelos de cuidado para com o idoso. Cien Saude Colet 2012; 17(1):231-238.

5. Camarano AA, Pasinato MT. O Envelhecimento Populacional na Agenda das Políticas Públicas. In: Camarano AA, organizadores. Os Novos Idosos Brasileiros: muito além dos 60 ? Rio de Janeiro: IPEA; 2004. p. 253-292.

6. Geib LTC. Determinantes sociais da saúde do idoso. Cien Saude Colet 2012; 17(1):123-133.

7. Bardin L. Análise de Conteúdo. Lisboa: Edições 70; 2011.

8. Brasil. Lei $\mathrm{n}^{\circ}$ 8.842, de 4 de janeiro de 1994. Dispõe sobre a Política Nacional do Idoso, cria o Conselho Nacional do Idoso e dá outras providências. Diário Oficial da União 1994; 4 jan.

9. Brasil. Decreto $\mathrm{n}^{\circ} 1.948$, de 3 de julho de 1996. Regulamenta a Lei $\mathrm{n}^{\circ} 8.842$, de 4 de janeiro de 1994, que dispõe sobre a Política Nacional do Idoso, e dá outras providências. Diário Oficial da União 1996; 4 jul.

10. Brasil. Decreto 4.227, de 13 de maio de 2002. Cria o Conselho Nacional dos Direitos do Idoso - CNDI, e dá outras providências. Diário Oficial da União 1996; 14 maio.

11. Brasil. Lei 10.741 , de 1 de outubro de 2003. Dispõe sobre o Estatuto do Idoso e dá outras providências. Diário Oficial da União 2003; 3 out.

12. Brasil. Portaria 399/GM, de 22 de fevereiro de 2006. Divulga o Pacto pela Saúde 2006 - Consolidação do SUS e aprova as Diretrizes Operacionais do Referido Pacto. Diário Oficial da União 1996; 23 fev.

13. Brasil. Portaria n. 2.528, de 19 de outubro de 2006. Aprova a Política Nacional de Saúde da Pessoa Idosa e determina outras providências. Diário Oficial da União 2006; 19 out.

14. Brasil. Portaria do Gabinete do Ministro de Estado da Saúde de n 1395, de 9 de dezembro de 1999. Aprova a Política Nacional de Saúde do Idoso e dá outras providências. Diário Oficial da União 1999; 9 dez.

15. Alves VP, Vianna LG. Políticas públicas para a educação gerontológica na perspectiva da inserção social do idoso: desafios e possibilidades. Ensaio: aval. Pol. Públ. Educ. 2010; 18(68):489-510.

16. Laranjeira CA. "Velhos são os Trapos": do positivismo clássico à nova era. Saúde Soc 2010; 19(4):763-770.

17. Camacho ACLF, Coelho MJ. Políticas públicas para a saúde do idoso: revisão sistemática. Rev Bras Enferm 2010; 2(63):279-784. 
18. Telles JL. A construção das políticas públicas nos espaços democráticos de participação cidadã: a violência contra pessoas idosas na agenda do movimento social. Cien Saude Colet 2010; 15(6): 2669-2671.

19. Martins MS, Massarollo MCKB. Conhecimento de idosos sobre seus direitos. Acta Paul Enferm 2010; 4(23):479-485.

20. Alencar MSS, Carvalho CMRG. O envelhecimento pela ótica conceitual, sociodemográfica e políticoeducacional: ênfase na experiência piauiense. Interface (Botucatu) 2009; 13(29):435-444.

21. Cielo PFLD, Vaz ERC. Legislação brasileira e o idoso. Rev. CEPPG 2009; 2(21):33-46.

22. Moimaz SAS, Garbin CAS, Saliba NA, Lolli LF. Aspectos legislativos de relevância para profissionais de saúde. Rev Espaço para a Saúde 2009; 10(2):61-69.

23. Martins JJ, Schier J, Erdmann AL. Políticas públicas de atenção à saúde do idoso: reflexão acerca da capacitação dos profissionais da saúde para o cuidado com o idoso. Rev Bras Geriatr Gerontol 2007; 10(3):371-387.

24. Machado MAN. O movimento dos idosos: um novo movimento social. Revista Kairós 2007; 1(10):221233.

25. Veras R. Fórum Envelhecimento populacional e as informações de saúde do PNAD: demandas e desafios contemporâneos. Introdução. Cad Saude Publica 2007; 23(10):2463-2466.

26. Souza Júnior DGS, Kullok AT, Telles JL. A Agenda 21 Global e a Agenda 21 Brasileira: desafios para a inclusão social dos idosos. Comun Ciênc Saúde 2006; 4(17):291-302.

27. Camargos CN, Mendonça CA, Viana EMB. Política, estado e sociedade: o estatuto do idoso e a atenção a saúde. Comun Ciênc Saúde 2006; 17(3):217-227.

28. Telles SMBS. Idoso: Família, Trabalho e Previdência [tese]. Campinas (SP): Unicamp; 2003.
29. Kalache A. O mundo envelhece: é imperativo criar um pacto de solidariedade social. Cien Saude Colet 2008; 4(13):1107-1111.

30. Veras R. Envelhecimento, demandas, desaûos e inovações. Rev Saude Publica 2009; 3(43):548-554.

31. Brasil. Ministério da Saúde (MS). Secretaria de Atenção à Saúde. Departamento de Atenção Básica. Política Nacional de Alimentação e Nutrição. 2a Edição. Brasília: MS; 2003.

32. World Health Organization (WHO). Active ageing: a policy framework. Madrid: WHO; 2002. Second United Nations World Assembly on Ageing.

33. Brasil. Portaria no 702/SAS/MS, de 12 de abril de 2012. Dispõe sobre a criação de mecanismos para a organização e implantação de Redes Estaduais de Assistência à Saúde do Idoso. Diário Oficial da União 2012; 13 abr.

34. Brasil. Portaria no 249/SAS/MS, de 16 de abril de 2002. Diário Oficial da União 2012; 17 abr.

35. Brasil. Constituição da República Federativa do Brasil de 1988. Diário Oficial da União 1988; 5 out.

Artigo apresentado em 15/03/2012

Aprovado em 26/03/2012

Versão final apresentada em 28/03/2012 